\title{
Pengaruh Kombinasi Pupuk Hayati Endomikoriza, Trichoderma spp., dan Pupuk Kompos terhadap Pertumbuhan Bibit Sengon (Paraserianthes falcataria (L.) Nielsen)
}

\author{
Effect of Bio-Fertilizer, Endomicorrhiza, Trichoderma spp., and Compost \\ Combination on the Growth of Sengon Seedlings (Paraserianthes falcataria \\ (L.) Nielsen) \\ Oleh: \\ Putu Mita Krisdayani, Meitini Wahyuni Proborini*, Eniek Kriswiyanti \\ Program Studi Biologi, Fakultas Matematika dan Ilmu Pengetahuan Alam, Universitas Udayana. Jl. Raya \\ Kampus Unud No. 9, Badung, 80361, Bali, Indonesia \\ *E-mail: pmeitini@unud.ac.id
}

\begin{abstract}
ABSTRAK
Sengon (Paraserianthes falcataria (L.) Nielsen) merupakan jenis pohon multiguna yang umumnya ditanam di hutan rakyat dengan sistem agroforestri. Untuk mendapatkan pohon sengon yang berkualitas maka diperlukan bibit yang berkualitas baik. Selain itu, pemberian pupuk hayati dan pupuk organik pada fase pembibitan juga diperlukan. Penelitian ini bertujuan untuk mengetahui pengaruh pemberian kombinasi jamur Trichoderma spp., endomikoriza, dan pupuk kompos terhadap petumbuhan bibit tanaman sengon, serta menentukan perbandingan dosis yang optimum dari kombinasi Trichoderma spp., endomikoriza, dan kompos untuk meningkatkan pertumbuhan bibit sengon. Penelitian dilakukan di Laboratorium Taksonomi Tumbuhan (Mikologi) dan di Balai Pengelolaan Daerah Aliran Sungai dan Hutan Lindung Unda Anyar di Bali. Penelitian ini menggunakan 6 perlakuan, yaitu: A (tanah steril atau tanpa perlakuan), B (tanah steril dan $10 \mathrm{~g}$ pupuk kompos), C (10 ml Trichoderma spp.), D (10 ml Trichoderma spp., 100 spora endomikoriza, dan $10 \mathrm{~g}$ pupuk kompos), E (10 ml Trichoderma spp., 150 spora endomikoriza dan 10 g pupuk kompos), dan F (10 ml Trichoderma spp., 200 spora endomikoriza dan $10 \mathrm{~g}$ pupuk kompos). Penelitian ini terdiri dari 5 kelompok dengan 3 sub-unit tanaman. Hasil penelitian menunjukkan bahwa kombinasi jamur Trichoderma spp., endomikoriza, dan pupuk kompos menunjukkan pengaruh nyata terhadap tinggi tanaman, jumlah cabang tangkai daun, berat basah tanaman, berat kering tanaman, dan berat kering akar bibit tanaman sengon dibanding dengan kontrol namun tidak berpengaruh terhadap berat basah akar. Kombinasi inokulum $10 \mathrm{ml}$ Trichoderma spp., 150 spora endomikoriza, dan $10 \mathrm{~g}$ pupuk merupakan dosis yang optimal dan efektif untuk meningkatkan pertumbuhan bibit sengon.
\end{abstract}

Kata kunci: bibit sengon, mikoriza, tanaman kayu

\section{ABSTRACT}

Sengon (Paraserianthes falcataria (L.) Nielsen) is a tree species commonly planted in community forests and managed using an agroforestry system. In order to grow a high-quality sengon tree, high-quality seeds are essentials. In addition, providing biofertilizers and organic fertilizers during the nursery phase is necessary. This study aimed to determine the effect of Trichoderma spp., endomycorrhizae, and compost fertilizer combination on the growth of sengon (Paraserianthes falcataria (L.) Nielsen) seeds and to determine the optimum ratio to 
increase the growth of sengon seeds. The research was performed in the Plant Taxonomy Laboratory (Mycology) and Unda Anyar Watershed and Protected Forest Management Office in Bali. The research was performed with six treatments, namely: A (sterile or untreated soil), $B$ (sterile soil and $10 \mathrm{~g}$ of compost), C (10 ml Trichoderma spp.), D (10 ml Trichoderma spp., 100 endomycorrhizal spores, and $10 \mathrm{~g}$ compost), E (10 ml Trichoderma spp., 150 endomycorrhizal spores, and $10 \mathrm{~g}$ compost), and $F(10 \mathrm{ml}$ Trichoderma spp., 200 endomycorrhizal spores, and $10 \mathrm{~g}$ compost). This study consisted of five groups with three subunit plants. The results showed that the combination of Trichoderma spp., endomycorrhizae, and compost fertilizer significantly increased plant height, amount of stem branches, fresh weight and dry weight of plant, and dry weight of root compared to control. However, the effect on the root fresh weight was not significant. A combination of $10 \mathrm{ml}$ Trichoderma spp., 150 endomycorrhizal spores, and $10 \mathrm{~g}$ of compost fertilizer was the most optimal and effective in increasing the growth of sengon seeds.

Keywords: mycorrhiza, sengon seedlings, woody plants

\section{PENDAHULUAN}

Sengon (Paraserianthes falcataria (L.) Nielsen) merupakan tanaman yang sering dikembangkan sebagai jenis pada hutan rakyat dengan menerapkan sistem agroforestri (Sari et al. 2018). Tanaman ini memiliki sifat yang menguntungkan karena memiliki nilai yang komersial dan tidak menuntut persyaratan tempat untuk tumbuh (Zakiyah et al. 2017). Sengon dapat dimanfaatkan sebagai kayu kontruksi ringan dan furnitur. Jika dibandingkan dengan kayu lainnya, kayu sengon memiliki sifat fisik yang unggul untuk industri kertas karena kayu sengon memiliki panjang serat yang paling tinggi sehingga kertas dari kayu sengon memiliki sifat tahan robek (Priadi dan Hartati 2018). Namun tanaman sengon memiliki kelemahan yaitu rentan terkena penyakit karat dan lodoh (Rahayu 2014).

Menurut Rahayu (2014), tanaman sengon memiliki kerentanan terhadap penyakit karat tumor (gall rust) yang disebabkan oleh jamur Uromycladium tepperianum. Penyakit karat tumor dapat menghambat pertumbuhan tanaman, cacat tanaman, cacat pada batang yang dapat mengurangi volume dan kualitas kayu dan dapat menyebabkan kematian pada tanaman sengon. Infeksi mikroorganisme yang tidak menguntungkan bagi tanaman dapat menyebabkan penyakit pada tanaman sengon. Balai pembenihan sengon juga bahwa pada fase pembibitan, sengon rentan terkena penyakit lodoh yang disebabkan oleh jamur Phytium sp., Phytophthora sp., dan Rhizoctonia sp. (Krisnawati et al. 2011). Untuk meningkatkan pertumbuhan dan keberhasilan penanaman sengon maka perlu dilakukan pemberian pupuk hayati dan pupuk kompos.

Salah satu jamur yang dapat dimanfaatkan untuk mengurangi penyakit pada tanaman adalah jamur Trichoderma spp. Trichoderma spp dapat mengendalikan pertumbuhan patogen tular tanah yaitu Sclerotonia sp., Fusarium sp., Phytium sp. dan Rhizoctonia sp (Intan et al. 2013). Hal tersebut sesuai dengan Gusnawaty et al. (2014) jamur Trichoderma spp. merupakan mikroorganisme tanah yang menguntungkan tanaman. Aplikasi jamur Trichoderma spp. selain melindungi dari penyakit juga terbukti dapat mendukung pertumbuhan tanaman seperti meningkatkan panjang akar tanaman, bobot buah, dan bobot kering benih sedangkan endomikoriza mampu meningkatkan panjang tanaman, jumlah daun, bobot segar akar, bobot kering akar, dan bobot kering total tanaman (Valentine et al. 2018).

Unsur hara sangat diperlukan untuk meningkatkan pertumbuhan tanaman sengon, namun penggunaan pupuk anorganik secara terus-menerus dan berlebihan dapat menurunkan kesuburan tanah dan merusak lingkungan sehingga penggunaan pupuk anorganik harus dikurangi. Salah satu upaya untuk mengurangi penggunaan pupuk anorganik adalah dengan 
menggunakan pupuk hayati dan pupuk organik (Roni et al. 2019). Menurut Nurhalimah et al. (2014) salah satu pupuk hayati yang sering digunakan sebagai alternatif adalah jamur endomikoriza. Keberadaan jamur endomikoriza sangat berlimpah di alam (Proborini et al. 2013) dan hampir lebih dari $80 \%$ jamur tersebut mampu bersimbiosis dengan tumbuhan angiospermae berperan penting dalam meningkatkan produktifitas tanaman agrikultur, hortikultura, perkebunan dan kehutanan (Proborini 2011).

Salah satu pupuk organik yang sering digunakan untuk mengurangi penggunaan pupuk anorganik adalah pupuk kompos. Pupuk kompos dapat mempebaiki sifat fisik tanah (Syam 2003). Kompos mengandung kandungan unsur hara seperti nitrogen dan fosfat dalam bentuk senyawa yang kompleks yang sangat sulit diserap oleh tanaman (Elpawati et al. 2016). Agar tanaman dapat memanfaatkan unsur-unsur tersebut, dibutuhkan jamur endomikoriza yang digunakan sebagai pupuk hayati atau biofertilizer (pelarut hara) (Suryatmana et al. 2009).

Penggunaan pupuk anorganik perlu dikurangi karena dapat menyebabkan pencemaran tanah dan lingkungan. Untuk mendapatkan bibit yang unggul yang siap untuk dipindahkan ke lahan agroforestri diperlukan pupuk hayati dan pupuk organik. Berdasarkan fakta tersebut, perlu dilakukan penelitian aplikasi pupuk hayati endomikoriza, Trichoderma spp., dan kompos pada pertumbuhan bibit sengon yang diharapkan mampu untuk mempercepat proses pembibitan dan ketahanan tanaman sengon pada fase pembibitan (nursery).

\section{METODE PENELITIAN}

Bahan penelitian yang digunakan adalah benih sengon (Paraserianthes falcataria (L.) Nielsen), media sapih berupa tanah, pasir, inokulum spora endomikoriza (Glomus sp.), suspensi Trichoderma spp., kompos, kentang, dextrose dan agar. Alat yang digunakan dalam penelitian ini berupa saringan bertingkat merk "Analysensieb Eckhardt 5657 Haan W. Germany", drum, sekop, polybag $15 \mathrm{~cm}$ x 7,5 cm, dan kotak kecambah ukuran $34 \mathrm{~cm}$ x $30 \mathrm{~cm}$ x $13 \mathrm{~cm}$.

Benih sengon direndam dengan air hangat dengan suhu $80^{\circ} \mathrm{C}$ dan dibiarkan sampai dingin selama 24 jam. Kemudian benih sengon dengan warna dan bentuk yang seragam disemai menggunakan kotak kecambah dengan media pasir. Setelah benih tumbuh dan memiliki 2-3 tangkai daun majemuk ( \pm 3-5 hari) maka telah siap dipindahkan ke dalam polybag. Penyemaian dan pertumbuhan bibit sengon dilakukan di Balai Pengelolaan Daerah Aliran Sungai dan Hutan Lindung, Tuban, Kuta, Kabupaten Badung, Bali. Kemudian dilakukan penyiapan media tanam menggunakan campuran tanah dan pasir 1:2 yang sebelum digunakan telah disterilisasi menggunakan drum (panci besar) dengan suhu $100^{\circ} \mathrm{C}$ selama 3 jam untuk mematikan sporaspora (mikroba patogen dan non patogen) yang terdapat di dalam tanah. Setelah disterilisasi tanah dipindahkan ke dalam polybag dengan ukuran $15 \mathrm{~cm}$ x 7,5 $\mathrm{cm}$ kemudian dibuat lubang tanam sedalam $5 \mathrm{~cm}$. Inokulasi Trichoderma spp. dilakukan dengan mengambil suspensi jamur Trichoderma spp. sebanyak $10 \mathrm{~mL}$ yang mengandung $1 \times 10^{6}$ spora Trichoderma spp. yang dihitung menggunakan hemasitometer. Suspensi yang telah berisi spora jamur dituangkan ke dalam lubang tanam pada masing-masing polybag satu kali sebelum benih sengon ditanam. Spora endomikoriza diinokulasikan ke dalam lubang tanam pada masing-masing polybag satu kali yaitu sebelum benih sengon ditanam. Pemberian pupuk kompos diberikan pada saat pencapuran media tanam.

Jamur Trichoderma spp. diperoleh dengan cara mereisolasi di media PDA (potato dextrose agar) dari biakan jamur koleksi laboratorium taksonomi tumbuhan (mikologi). sedangkan spora endomikoriza diambil dengan cara Teknik penyaringan dengan menggunakan saringan bertingkat merk "Analysensieb Eckhardt 5657 Haan W. Germany" dengan ukuran saringan $200 \mu \mathrm{m}, 100 \mu \mathrm{m}, 65 \mu \mathrm{m}$, dan $45 \mu \mathrm{m}$. Supernatan yang disaring pada air mengalir 
adalah saringan $65 \mu \mathrm{m}$ dan $45 \mu \mathrm{m}$. Spora endomikoriza diamati dibawah mikroskop dan dihitung sebanyak 100 spora, 150 spora, dan 200 spora.

Penelitian ini menggunakan Rancangan Acak Kelompok (RAK) dengan 6 perlakuan. Perlakuan yang diberikan terdiri atas : A (tanah steril atau tanpa perlakuan), B (tanah steril dan 10 g pupuk kompos), C (10 ml Trichoderma spp.), D (10 ml Trichoderma spp., 100 spora endomikoriza, dan $10 \mathrm{~g}$ pupuk kompos), D (10 ml Trichoderma spp., 100 spora endomikoriza, dan $10 \mathrm{~g}$ pupuk kompos), E (10 ml Trichoderma spp., 150 spora endomikoriza, dan $10 \mathrm{~g}$ pupuk kompos), dan F (10 ml Trichoderma spp., 200 spora endomikoriza, dan $10 \mathrm{~g}$ pupuk kompos). Penelitian ini terdiri dari 5 kelompok dengan 3 sub-unit tanaman, sehingga terdapat 90 bibit tanaman sengon (dengan 6 perlakuan x 5 kelompok x 3 sub-unit tanaman). Secara keseluruhan penelitian dilakukan selama 5 bulan (November 2019 hingga Maret 2020). Variabel pengamatan yang diamati adalah tinggi tanaman, jumlah cabang tangkai daun, berat basah basah total tanaman, berat basah akar, berat kering total tanaman, berat kering akar, dan persentase kolonisasi endomikoriza pada akar tanaman sengon.

Pengamatan akar yang terkolonisasi endomikoriza dilakukan dengan metode Kormanik dan McGraw (1982) yaitu clearing, staining, dan destaining. Tahap clearing dimulai dengan membersihkan akar tanaman dengan air, kemudian dari ujung akar dipotong sepanjang $3 \mathrm{~cm}$. Potongan akar selanjutnya direndam dalam larutan $\mathrm{KOH} 10 \%$ selama 24 jam hingga akar tampak transparan menjadi tak berwarna. Setelah proses perendaman, akar dibilas menggunakan air mengalir hingga bersih. Kemudian akar direndam kembali dalam larutan $\mathrm{HCl}$ 1\% selama 5-10 menit. Tahap selanjutnya adalah staining, yaitu akar yang telah melewati tahap clearing akan direndam selama 24 jam dalam larutan staining yang terdiri dari gliserin, asam asetat glacial,aquades dengan perbandingan 2:2:1, dan ditambah pewarna trypan blue 0,05\%. Setelah akar terwarnai, dilanjutkan ke tahap terakhir yaitu direndam lagi dalam larutan destaining guna mengurangi intensitas warna pada akar sehingga mempermudah pengamatan. Menurut Santi et al. (2019) rumus perhitungan presentase kolonisasi mikoriza pada akar tanaman yaitu:

$$
\begin{gathered}
\text { kolonisasi mikoriza } \\
\text { pada akar }
\end{gathered}=\frac{\text { Jumlah akar terkolonisasi }(+)}{\text { Jumlah akar yang diamati }} \times 100 \%
$$

Data kuantitatif diperoleh pada penelitian ini dianalisis berdasarkan statistik. Pengolahan data kuantitatif menggunakan analisis sidik ragam atau analysis of varians (ANOVA) dengan uji-F 5\%. Jika terdapat perbedaan yang nyata antara perlakuan, dilanjutkan dengan uji nilai tengah perlakuan (BNT).

\section{HASIL DAN PEMBAHASAN}

\section{Hasil}

Hasil pengamatan selama 60 hari di lapangan menunjukkan bahwa pengaruh perlakuan $\mathrm{E}$ (10 ml Trichoderma spp., 150 spora endomikoriza, dan $10 \mathrm{~g}$ pupuk kompos) memberikan hasil tertinggi terhadap seluruh parameter yang diamati, yaitu tinggi tanaman, jumlah cabang tangkai daun, berat basah tanaman, berat basah akar, berat kering tanaman, berat kering akar dan presentase kolonisasi endomikoriza.

Hasil analisis ragam menunjukkan hasil yang signifikan pada parameter tinggi tanaman, jumlah daun, berat basah tanaman, berat kering tanaman, berat kering akar dan presentase kolonisasi endomikoriza pada akar. Untuk mengetahui dosis manakah yang memberikan pengaruh nyataterhadap parameter tersebut dilakukan uji BNT. Hasil uji BNT pengaruh pemberian pupuk hayati endomikoriza, Trichoderma spp., dan pupuk kompos terhadap pertumbuhan bibit sengon Tabel 2 . 
Tabel 1. Hasil analisis ragam pengaruh pemberian pupuk hayati endomikoriza, Trichoderma spp., dan pupuk kompos terhadap pertumbuhan bibit sengon (Paraserianthes falcataria (L.) Nielsen).

\begin{tabular}{llllllll}
\hline Perlakuan & TT & JD & BBT & BBA & BKT & BKA & \% EM \\
\hline F hitung & 2,68 & 4,47 & 3,319 & 1,650 & 3,409 & 3,402 & 248,723 \\
F tabel & 2,62 & 2,62 & 2,62 & 2,62 & 2,62 & 2,62 & 2,62 \\
\hline
\end{tabular}

Keterangan: $\mathrm{TT}=$ tinggi tanaman, $\mathrm{JD}=$ jumlah daun, $\mathrm{BBT}=$ berat basah tanaman, $\mathrm{BBA}=$ berat basah akar, $\mathrm{BKT}$ $=$ berat kering tanaman, dan $\mathrm{BKA}=$ berat kering akar.

Tabel 2. Hasil Uji BNT pengaruh pemberian pupuk hayati endomikoriza, Trichoderma spp., dan pupuk kompos terhadap pertumbuhan bibit sengon (Paraserianthes falcataria (L.) Nielsen).

\begin{tabular}{cccccccc}
\hline Perlakuan & \multicolumn{7}{c}{ Parameter } \\
& TT & JD & BBT & BBA & BKT & BKA & $\%$ EM \\
\hline A & $7,40^{\mathrm{b}}$ & $30,20^{\mathrm{b}}$ & $1,14^{\mathrm{b}}$ & $0,60^{\mathrm{b}}$ & $0,35^{\mathrm{b}}$ & $0,20^{\mathrm{b}}$ & \\
B & $8,00^{\mathrm{b}}$ & $34,80^{\mathrm{bcd}}$ & $1,80^{\mathrm{ab}}$ & $0,90^{\mathrm{b}}$ & $0,68^{\mathrm{ab}}$ & $0,28^{\mathrm{b}}$ & \\
C & $7,80^{\mathrm{b}}$ & $32,00^{\mathrm{bc}}$ & $1,20^{\mathrm{b}}$ & $0,70^{\mathrm{b}}$ & $0,50^{\mathrm{a}}$ & $0,22^{\mathrm{b}}$ & \\
D & $9,00^{\mathrm{ab}}$ & $43,6^{\mathrm{bc}}$ & $2,60^{\mathrm{a}}$ & $1,00^{\mathrm{b}}$ & $1,02^{\mathrm{a}}$ & $0,43^{\mathrm{ab}}$ & $46,6^{\mathrm{c}}$ \\
E & $9,80^{\mathrm{a}}$ & $47,00^{\mathrm{a}}$ & $3,00^{\mathrm{a}}$ & $1,08^{\mathrm{b}}$ & $1,05^{\mathrm{a}}$ & $0,60^{\mathrm{a}}$ & $54,60^{\mathrm{a}}$ \\
F & $8,80^{\mathrm{ab}}$ & $41,80^{\mathrm{abc}}$ & $2,20^{\mathrm{ab}}$ & $1,00^{\mathrm{b}}$ & $0,70^{\mathrm{ab}}$ & $0,32^{\mathrm{ab}}$ & $32,60^{\mathrm{b}}$ \\
\hline
\end{tabular}

Keterangan: Notasi super skrip pada nilai rata-rata pada kolom yang sama menunjukkan signifikasi. Perlakuan $\mathrm{A}=$ tanah steril atau tanpa perlakuan, $\mathrm{B}=$ tanah steril dan $10 \mathrm{~g}$ pupuk kompos, $\mathrm{C}=$ Tanah steril dan $10 \mathrm{ml}$ Trichoderma spp., $\mathrm{D}=10 \mathrm{ml}$ Trichoderma spp., 100 spora endomikoriza, dan $10 \mathrm{~g}$ pupuk kompos, $\mathrm{E}=10 \mathrm{ml}$ Trichoderma spp., 150 spora endomikoriza, dan $10 \mathrm{~g}$ pupuk kompos, dan $\mathrm{F}=10 \mathrm{ml}$ Trichoderma spp., 200 spora endomikoriza, dan $10 \mathrm{~g}$ pupuk kompos. $\mathrm{TT}=$ tinggi tanaman, $\mathrm{JD}=$ jumlah daun, $\mathrm{BBT}=$ berat basah tanaman, $\mathrm{BBA}=$ berat basah akar, $\mathrm{BKT}=$ berat kering tanaman, dan $\mathrm{BKA}=$ berat kering akar.

Berdasarkan nilai hasil uji BNT menunjukkan perlakuan E menunjukkan hasil yang berbeda nyata pada parameter tinggi tanaman, jumlah cabang tangkai daun, berat kering tanaman, berat kering akar, dan presentase kolonisasi endomikoriza tetapi menunjukkan hasil yang tidak berbeda nyata pada parameter berat basah akar.

\section{Pembahasan}

Pengaruh perlakuan terhadap pertumbuhan tanaman sengon (Paraserianthes falcataria (L.) Nielsen)

Berdasarkan data hasil penelitian menunjukkan bahwa pemberian jamur Trichoderma spp., endomikoriza, dan pupuk kompos mampu meningkatkan hasil rerata tertinggi pada tinggi tanaman, jumlah cabang tangkai daun, berat basah tanaman, berat basah akar, berat kering tanaman, berat kering akar, dan presentase kolonisasi endomikoriza dibandingkan dengan tanaman sengon tanpa perlakuan kedua jamur tersebut. Pemberian kombinasi Trichoderma spp., endomikoriza, dan pupuk kompos berpengaruh nyata terhadap tinggi tanaman sengon. Hal ini menunjukkan bahwa pemberian Trichoderma spp. dan endomikoriza yang diaplikasikan pada saat persemaiaan memungkinkan kedua jamur tersebut untuk berkoloni dengan baik pada perakaran tanaman sengon dan mampu meningkatkan laju pertumbuhan semai (Valentine et al. 2018). Tanaman sengon tanpa perlakuan menghasilkan tinggi tanaman yang lebih rendah dibandingkan dengan tanaman yang diberi perlakuan Trichoderma spp., endomikoriza, dan pupuk kompos. Hal ini dikarenakan spora mikoriza mampu bersimbiosis mutualisme dengan akar sehingga penyerapan unsur hara di dalam tanah menjadi lebih baik (Mayerni dan Hervani 2008). Menurut Wardhika et al. (2015), hifa endomikoriza merupakan bagian terpenting dari 
mikoriza, dikarenakan hifa ini mampu membantu penyerapan unsur hara tanah terutama unsur fosfor menjadi lebih besar dibandingkan dengan tanaman tidak bermikoriza.

Menurut Suharti et al. (2018), penambahan jamur Trichoderma sp. pada media bibit jabon merah dapat meningkatkan pertumbuhan tinggi tanaman, hal ini terjadi dikarenakan jamur ini mampu meningkatkan penyebaran unsur hara yang akan menyebabkan penambahan panjang akar dan panjang batang. Santi et al. (2019) pemberian Trichoderma harzianum, Trichoderma kononingii dan Trichoderma viridae mampu merangsang tanaman sehingga mampu menghasilkan hormon IAA dan giberelin yang dapat menunjang pertumbuhan tanaman.

Jumlah cabang tangkai daun pada perlakuan $\mathrm{D}$, E, dan $\mathrm{F}$ semakin meningkat dibandingkan dengan perlakuan yang tidak dilakukan pemberian endomikoriza, Trichoderma spp. dan kompos. Menurut Baskoro dan Purwoko (2012), meningkatnya jumlah daun berhubungan dengan tersedianya unsur nitrogen dalam media tumbuh, semakin banyak nitrogen di dalam tanah maka semakin banyak jumlah daun (Rokhminarsi et al. 2019). Pemberian jamur Trichoderma dapat meningkatkan kandungan unsur hara, mampu memperbaiki struktur tanah, membuat agregat atau butiran tanah menjadi besar, serta mampu menahan air sehingga aerasi di dalamnya menjadi lancar (Charisma et al. 2012). Menurut Cruz et al. (2004), jamur mikoria menginfeksi sistem perakaran tanaman inang lalu memproduksi jaringan hifa eksternal yang mampu menembus lapisan sub soil sehingga meningkatkan kapasitas akar dalam penyerapan hara dan air. Penyerapan unsur hara di dalam tanah mampu meningkatkan pertumbuhan tanaman, termasuk jumlah cabang (Nurhalimah et al. 2014).

Pemberian Trichoderma spp. dan endomikoriza juga diduga dapat meningkatkan pertumbuhan akar dan tajuk dibandingkan dengan tanaman tanpa perlakuan. Hal ini didukung dari hasil penelitian Gusta et al. (2017) pertumbuhan akar yang baik akibat inokulasi endomikoriza dapat meningkatkan pertumbuhan tajuk melalui tinggi tanaman kopi, diameter batang dan jumlah daun. Pemberian Trichoderma juga mampu menunjang pertumbuhan tanaman sengon karena jamur ini mampu menstimulasi tanaman untuk menghasilkan hormon yang auksin yang merangsang pembentukan akar lateral. Akar merupakan bagian yang berfungsi untuk menyerap unsur hara, air, dan zat terlarut di dalam tanah dan akan ditranfusikan ke bagian yang dibutuhkan oleh tanaman kemudian fotosintesis akan dimanfaatkan oleh tanaman yang akan mempengaruhi biomassa tanaman atau berat basah tanaman (Herlina dan Dewi 2010).

Berat basah akar ditimbang untuk mengetahui berapa besar air yang terkandung dalam akar tanaman tersebut. Pada berat basah akar yang paling tinggi dihasilkan oleh kombinasi Trichoderma spp., endomikoriza, dan pupuk kompos meski secara statistik menghasilkan data yang tidak berbeda nyata. Lingkungan yang mendukung untuk pertumbuhan mikoriza akan bersimbiosis baik dengan akar tanaman sehingga akan membuat hifa eksternal pada perakaran tanaman secara luas (Nasrullah et al. 2015).

Semakin tinggi berat kering tanaman, maka pertumbuhan tanaman tersebut akan semakin baik karena proses fotosintesis berjalan dengan lancar dan tanaman juga menyerap semakin banyak unsur hara dan air (Valentine et al. 2018). Pemberian Trichoderma spp., endomikoriza, dan pupuk kompos mampu menunjang pertumbuhan bibit tanaman sengon karena memiliki sistem perakaran dan penyerapan unsur hara lebih baik. Hal tersebut didukung oleh Wardhika et al. (2015) pemberian mikoriza dapat meningkatkan berat kering tanaman karena aktifitas hifa endomikoriza dalam melakukan penyerapan unsur hara $P$ juga terjadi melalui enzim fosfatase yang dihasilkan oleh jamur endomikoriza. Dengan adanya enzim fosfatase ion-ion $\mathrm{P}$ yang kompleks pada tanah akan terurai menjadi lebih sederhana dan dapat diserap oleh tanaman sedangkan pemberian Trichoderma spp. menurut Dendang dan Hani (2014), Trichoderma spp. mampu meningkatkan $\mathrm{pH}$ pupuk serta mampu meningkatkan kandungan unsur hara $\mathrm{N}$ dan $\mathrm{C}$ sehingga dapat meningkatkan produksi berat kering pada hasil akhir tanaman. 
Berat kering akar tertinggi dihasilkan oleh perlakuan E (10 ml Trichoderma spp., 150 spora endomikoriza, dan $10 \mathrm{~g}$ pupuk kompos) yaitu dengan rata-rata sebesar $0,60 \mathrm{~g}$ dan berat kering akar terendah didapatkan pada perlakuan A (tanah steril atau tanpa perlakuan) yaitu sebesar 0,20 g. Pada perlakuan C (10 ml Trichoderma spp.) menunjukan hasil yang tidak berbeda nyata dengan perlakuan A (tanpa perlakuan).

Berat kering akar tertinggi dihasilkan oleh pemberian jamur Trichoderma spp., endomikoriza, dan $10 \mathrm{~g}$ pupuk kompos. Hal ini didukung oleh penelitian Ristiyanti et al. (2014), bahwa pemberian endomikoriza mampu meningkatkan berat kering pada semai kemiri (Aleurites moluccana) dikarenakan akar tanaman yang berkolonisasi dengan endomikoriza akan memperluas bidang serapan akar dengan adanya hifa eksternal yang tumbuh dan berkembang pada bulu akar. Tanaman bermikoriza memiliki kemampuan untuk menyerap unsur hara P dan unsur hara lain seperti N, K, dan Mg. Hal ini dikarenakan mikoriza memiliki hifa-hifa akar yang akan tumbuh lebih panjang dibandingkan tanaman tanpa mikoriza sehingga tanaman bermikoriza memiliki berat akar yang semakin tinggi (Hartoyo et al. 2011).

\section{Dosis optimum yang efektif untuk pertumbuhan bibit sengon}

Berdasarkan hasil penelitian, perlakuan E (10 ml Trichoderma spp., 150 spora endomikoriza, dan $10 \mathrm{~g}$ pupuk kompos) memberikan pertumbuhan yang optimal terhadap bibit tanaman sengon. Pertumbuhan yang optimal ini dipengaruhi asosiasi endomikoriza pada akar yang dimana infeksi yang tinggi memberikan respon positif terhadap tanaman (Yusrizal et al. 2018).

Kolonisasi endomikoriza pada akar dapat dilihat di bawah mikroskop dengan adanya hifa, vesikel, arbuskular, dan spora pada akar bibit tanaman sengon. Presentase kolonisasi endomikoriza terdapat pada perlakuan D, E, dan F, sedangkan untuk perlakuan A, B, dan C tidak terdapat kolonisasi karena tidak dilakukan inokulasi endomikoriza. Adanya kolonisasi endomikoriza pada perlakuan D, E, dan F dikarenakan perlakuan tersebut mendapat perlakuan endomikoriza.

Infeksi endomikoriza pada akar dipengaruhi oleh beberapa faktor antara lain, suhu, $\mathrm{pH}$, kelembaban, dan tanah. Suhu yang relatif tinggi akan meningkatkan aktifitas mikoriza. Suhu optimum untuk perkecambahan spora sangat beragam bergantung dengan jenisnya. Suhu $35^{\circ} \mathrm{C}$ tidak menghambat perkembangan atau pun aktivitas mikroiza pada akar namun ketika suhu di atas $40^{\circ} \mathrm{C}$ aktivitas mikroriza pun akan menurun (Rahmi et al. 2017). Tanah sampel penelitian didominasi dengan pasir. Menurut Anggreiny et al. (2017), tanah berpasir biasanya memiliki kandungan unsur hara yang rendah. Semakin rendah unsur P maka semakin baik perkembangan endomikoriza pada lahan tersebut.

Hasil rerata perhitungan mikoriza pada akar menunjukkan kolonisasi terbanyak terdapat pada perlakuan E (10 ml Trichoderma spp., 150 spora endomikoriza, dan $10 \mathrm{~g}$ pupuk kompos) yaitu sebesar 54\% sehingga menghasilkan pertumbuhan bibit tanaman sengon dengan rerata tertinggi untuk semua parameter. Hasil penelitian Charisma et al. (2012) tanaman kedelai yang diberi perlakuan kompos Tichoderma dan mikoriza sebanyak $45 \mathrm{~g}$ menghasilkan rata-rata yang paling optimal untuk setiap parameter yang diamati, yaitu presentase infeksi MVA, tinggi tanaman, panjang akar, dan biomassa tanaman. Kompos Trichoderma dapat dikombinasikan dengan mikoriza karena dapat mempercepat pertumbuhan tanaman, perkembangan akar, dan meningkatkan unsur hara P. Hasil penelitian (Valentine et al. 2018) menunjukkan bahwa Trichoderma spp. mampu meningkatkan panjang akar tanaman, bobot buah, dan bobot kering benih yang dipengaruhi oleh pemberian mikoriza.

Perlakuan F (10 ml Trichoderma spp., 200 spora endomikoriza, dan $10 \mathrm{~g}$ pupuk kompos) menyebabkan penurunan pertumbuhan bibit sengon. Hal ini menunjukkan bahwa kolonisasi yang tinggi tidak bergantung hanya kepada jumlah spora yang diberikan tetapi juga bergantung pada kemampuan spora untuk mematahkan dormansi dan kemampuan spora untuk melakukan 
germinasi dan berkolonisasi dengan inangnya. Menurut Rajmi et al. (2018) pemberian endomikoriza yang terlalu sedikit (rendahnya kerja endomikoriza) dan pemberian endomikoriza yang berlebihan dapat menyebabkan terjadinya kompetisi antar endomikoriza sehingga hasil yang didapatkan menjadi tidak optimal. Semakin banyaknya dosis endomikoriza maka akan terjadinya persaingan untuk berkolonisasi pada akar tanaman (Nurmasyitah et al. 2013).

Hasil analisis tanah yang dilakukan sebelum penelitian menunjukkan unsur P pada tanah sebesar 133,161 mg/kg. Menurut Aulia et al. (2016), pemberian endomikoriza pada akar tanaman menyebabkan unsur P yang kompleks pada tanah akan terurai dan dapat diserap oleh akar tanaman. Hal ini dikarenakan endomikoriza merupakan jamur perlarut fostat. Jamur perlarut fosfat merupakan jamur yang mampu mengubah fosfat yang berada dalam tanah dari bentuk senyawa (sulit terlarut) menjadi bentuk ion (mudah terlarut) sehingga dapat dimanfaatkan oleh tanaman (Priyanta et al. 2019). Tingginya serapan P oleh tanaman yang terinfeksi oleh endomikoriza disebabkan oleh hifa endomikoriza yang mengeluarkan enzim fosfatase sehingga P yang terikat di dalam tanah akan terlarut dan tersedia bagi tanaman (Aulia et al. 2016).

\section{SIMPULAN}

Kombinasi pupuk hayati endomikoriza, Trichoderma spp., dan pupuk kompos meningkatkan pertumbuhan bibit tanaman sengon pada tinggi tanaman, jumlah cabang tangkai daun, berat basah tanaman, berat kering tanaman, berat kering akar. Kombinasi 150 spora endomikoriza, $10 \mathrm{ml}$ Trichoderma spp., dan $10 \mathrm{~g}$ pupuk kompos merupakan dosis yang optimal dan efektif dalam meningkatkan pertumbuhan pada bibit tanaman senon (Paraserianthes falcataria (L.) Nielsen).

\section{SAWACANA}

Ucapan terima kasih terutama ditujukan kepada Balai Pengelolaan Daerah Aliran Sungai dan Hutan Lindung Unda Anyar, Tuban, Kuta, Kabupaten Badung, Bali (BPDAS) yang telah memfasilitasi, mendukung kegiatan penelitian dan Laboratorium Mikologi FMIPA Universitas Udayana yang telah menyediakan sarana dan fasilitas dalam penelitian ini.

\section{DAFTAR PUSTAKA}

Anggreiny, Y., Nazip, K., and Santri, D. J. 2017. Identifikasi Fungi Mikoriza Arbuskula (FMA) pada Rhizosfir Tanaman di Kawasan Revegetasi Lahan Penambangan Timah di Kecamatan Merawang Kabupaten Bangka dan Sumbangannya pada Pembelajaran Biologi SMA. in: Prosiding Seminar Nasional Pendidikan IPA 2017 391-403.

Aulia, F., Susanti, H., and Fikri, E. N. 2016. Pengaruh Pemberian Pupuk Hayati dan Mikoriza Terhadap Intensitas Serangan Penyakit Layu Bakteri (Ralstonia solanacearum), Pertumbuhan, dan Hasil Tanaman Tomat. Jurnal Ziraa'ah 41(2): 250-260.

Baskoro, D., and Purwoko, B. S. 2012. Pengaruh Bahan Perbanyakan Tanaman dan Jenis Pupuk Organik Terhadap Pertumbuhan Tanaman Binahong (Anredera cordifolia (Ten.) Steenis). Jurnal Hortikultura Indonesia 2(1): 6. DOI: 10.29244/jhi.2.1.6-13

Cruz, C., Green, J. J., Watson, C. A., Wilson, F., and Martins-Loução, M. A. 2004. Functional aspects of root architecture and mycorrhizal inoculation with respect to nutrient uptake 
capacity. Mycorrhiza 14(3): 177-184. DOI: 10.1007/s00572-003-0254-5

Dendang, B., and Hani, A. 2014. Efektivitas Trichoderma spp. dan Pupuk Kompos Terhadap Pertumbuhan Bibit Sengon (Falcataria Mollucana). Jurnal Penelitian Agroforestry 2(1): $13-19$.

Elpawati, E., Dara, S. D., and Dasumiati, D. 2016. Optimalisasi Penggunaan Pupuk Kompos dengan Penambahan Effective Microorganism 10 (Em10) pada Produktivitas Tanaman Jagung (Zea mays L.). Jurnal Biologi E-Journal System Portal of Syarif Hidayatullah State Islamic University 8(2): 77-87. DOI: 10.15408/kauniyah.v8i2.2693

Gusta, A. R., Rofiq, M., and Fatahillah, F. 2017. Efektivitas Pupuk Hayati (Inokulan Cendawan Mikoriza Arbuskula dan Trichoderma) dan Pupuk P pada Karakter Fisiologis, Pertumbuhan dan Produksi Nilam (Pogostemon cablin Benth.). Prosiding Seminar Nasional Pengembangan Teknologi Pertanian (September): 79-83. DOI: 10.25181/prosemnas.v0i0.734

Hartoyo, B., Ghulamahdi, M., Darusman, L. K., Aziz, S. A., and Mansur, I. 2011. Keanekaragaman Fungi Mikoriza Arbuskula (fma) pada Rizosfer Tanaman Pegagan (Centella Asiatica (L.) Urban). Jurnal Penelitian Tanaman Industri 17(1): 32-40. DOI: 10.21082/littri.v17n1.2011.32 - 40

Herlina, L., and Dewi, P. 2010. Penggunaan Kompos Aktif Trichoderma sp. dalam Meningkatkan Pertumbuhan Tanaman Cabai. Jurnal Sains dan Teknologi (Sainteknol) 8(2): 11-17. DOI: 10.15294/sainteknol.v8i2.317

HS, G., Taufik, M., Triana, L., and Asniah. 2014. Karakterisasi morfologis Trichoderma spp. indigenus Sulawesi Tenggara. Jurnal Agroteknos 4(2): 88-94.

Intan, B., Setyawan, B., and Hadi, H. 2013. Mekanisme antagonisme Trichoderma sp. terhadap beberapa patogen tular tanah. Balai Penelitian Getas, Salatiga. Warta Perkaretan 32(2): 74-82.

Kormanik, P. P., and McGraw, A. C. 1982. Quantification of Vesicular-Arbuscular Mycorrhizae in Plant Roots. in: Methods and Principles of Mycorrhizal Research N. C. Schenk, ed. APS Press, Minneapolis.

Krisnawati, H., Varis, E., Kallio, M., and Kanninen, M. 2011. Paraserianthes falcataria (L.) Nielsen: Ekologi, Silvikultur dan Produktivitas. Center for International Forestry Research (CIFOR), Bogor, Indonesia. DOI: 10.17528/cifor/003482

Mayerni, R., and Hervani, D. 2008. Pengaruh jamur mikoriza arbuskula terhadap pertumbuhan tanaman selasih (Ocimum sanctum L.). Jurnal Akta Agrosia 11(1): 7-12.

Mega Charisma, A., Sri Rahayu, Y., and Jurusan Biologi, I. 2012. Pengaruh Kombinasi Kompos Trichoderma dan Mikoriza Vesikular Arbuskular (MVA) terhadap Pertumbuhan Tanaman Kedelai (Glycine max (L.) Merill) pada Media Tanam Tanah Kapur. LenteraBio: Berkala Ilmiah Biologi 1(3): 111-116.

Nasrullah, Nurhayati, and Marliah, A. 2015. Pengaruh Dosis Pupuk NPK (16:16:16) dan Mikoriza terhadap Pertumbuhan Bibit Kakao (Theobroma cacao L.) pada Media Tumbuh Subsoil. Jurnal Agrium 12(2): 56-64.

Nurhalimah, S., Nurhatika, S., and Muhibuddin, A. 2014. Eksplorasi Mikoriza Vesikular Arbuskular ( MVA ) Indigenous Pada Tanah Regosol di Pamekasan, Madura. Jurnal Sains dan Seni Pomits 3(1): 30-34.

Nurmasyitah, N., Syafruddin, S., and Sayuthi, M. 2013. Pengaruh Jenis Tanah dan Dosis Fungi Mikoriza Arbuskular Pada Tanaman Kedelai Terhadap Sifat Kimia Tanah. Jurnal Agrista 17(3): 103-110.

Priadi, D., and Hartati, N. S. 2018. Karakterisasi Sengon (Paraserianthes falcataria L. Nielsen) Unggul Berdasarkan Morfologi Pohon dan Kadar Lignin. in: Prosiding Seminar Nasional XVII "Kimia dalam Pembangunan " 341-350.

Priyanta, R. D., Proborini, M. W., and Raka Dalem, A. A. 2019. Eksplorasi dan Identifikasi 
Jamur Pelarut Fosfat di Kawasan Hutan Taman Nasional Bali Barat (TNBB). Jurnal Metamorfosa 6(1): 131-136. DOI: 10.3923/pjbs.2003.514.524

Proborini, M. W. 2011. Eksplorasi jenis-jenis endomikoriza indigenus pada lahan kering di Bali dan Pemanfaatannya. Laporan Hibah Doktor.

Proborini, M. W., Sudana, M., Suarna, W., and Ristiati, N. P. 2013. Indigenous Vesicular Arbuscular Mycorrhizal (VAM) Fungi in Cashew Nut (Anacardium occidentale L.) Plantation of North East-Bali Island - Indonesia. Journal of Biology, Agriculture and Healthcare 3(3): 114-121.

Rahayu, S. 2014. Strategi Pengelolaan Penyakit Tanaman Hutan di Indonesia: Penyakit Karat Tumor Pada Tanaman Sengon (Falcataria Mullucana). UGM Press, Yogyakarta, Indonesia.

Rahmi, N., Dewi, R., Maretalina, R., and Hidayat, M. 2017. Keanekaragaman Fungi Mikoriza di Kawasan Hutan Desa Lamteuba Droe Kecamatan Seulimum Kabupaten Aceh Besar. Prosiding Seminar Nasional Biotik 4(1): 227-236.

Rajmi, S. L., Margarettha, and Refliaty. 2018. Peningkatan Ketersediaan P Ultisol dengan Pemberian Fungi Mikoriza Arbuskular. Journal Agroecotania 1(2): 42-48.

Ristiyanti, Yusran, and Rahmawati. 2014. Pengaruh Beberapa Spesies Fungi Mikoriza Arbuskular pada Media Tanah dengan pH Berbeda terhadap Pertumbuhan Semai Kemiri (Aleurites moluccana (L.) Willd.). Warta Rimba 2(2): 117-124.

Rokhminarsi, E., Utami, D. S., and Begananda. 2019. Aplikasi Pupuk Mikotricho ( MikorizaTrichoderma ) dan Pupuk Sintetik pada Budidaya Cabai Merah. Jurnal Hortikultura Indonesia 10(3): 154-160.

Roni, N. G. K., Kusumawati, N. N. C., Witariadi, N. M., Lindawati, S. A., and Siti, N. w. 2019. Produksi dan Karakteristik Kacang Pinto yang Diberi Pupuk Kandang Sapi dan Mikoriza. Pastura 6(2): 94-97. DOI: 10.24843/pastura.2017.v06.i02.p11

Santi, W. P., Defiani, M. R., and Proborini, M. W. 2019. Potensi Inokulasi Jamur Trichoderma viride dan Glomus sp. terhadap Produktivitas Capsicum annuum L. Jurnal Mikologi Indonesia 3(2): 95-103. DOI: 10.46638/jmi.v3i2.61

Sari, R. R., Hairiah, K., and Suyanto, S. 2018. Karakteristik Hutan Rakyat Jati dan Sengon Serta Manfaat Ekonominya di Kabupaten Malang. Jurnal Ekonomi Pertanian dan Agribisnis 2(2): 129-137. DOI: 10.21776/ub.jepa.2018.002.02.6

Suharti, T., Bramasto, Y., and Yuniarti, N. 2018. Pengaruh Pemberian Trichoderma sp. pada Media Tanam dan Mankozeb Terhadap Presentase Tumbuh dan Pertumbuhan Bibit Jabon Merah (Anthocepalus macrophyllus). Jurnal Perbenihan Tanaman Hutan 6(1): 41-48. DOI: $10.20886 /$ bptpth.2018.6.1.41-48

Suryatmana, P., Satiawati, M. R., and Rataseca, P. 2009. Peranan Mikofer dan Bahan organik kascing dalam translokasi $\mathrm{Pb}$, serapan fosfor dan hasil tanaman cabai (Capsicum annum) pada tanah tercampur logam berat. Bandung: Universitas Padjajaran.

Syam, A. 2003. Efektivitas pupuk organik dan anorganik terhadap produktivitas padi di lahan sawah. Jurnal Agrivigor 3(2): 232-244.

Valentine, K., Herlina, N., and Aini, N. 2018. Pengaruh Pemberian Mikoriza dan Trichoderma sp. Terhadap Pertumbuhan Dan Hasil Produksi Benih Melon Hibrida (Cucumis melo L.). Jurnal Produksi Tanaman 5(7): 1085-1092. DOI: 10.21176/PROTAN.V5I7.481

Wardhika, C. M., Hadisutrisno, B., and Widada, J. 2015. Potensi Jamur Mikoriza Arbuskular Unggul dalam Peningkatan Pertumbuhan dan Kesehatan Bibit Tebu (Saccharum officinarum L.). Ilmu Pertanian 18(2): 84-91.

Yusrizal, Muyassir, and Syafruddin. 2018. Optimalisasi Tanah Kritis dengan Mikoriza dan Fosfat untuk Peningkatan Pertumbuhan dan Serapan Hara Kedelai. Jurnal Agrotek Lestari 5(1): 100-112. DOI: 10.35308/jal.v4i1.641

Zakiyah, R., Siregar, U. J., and Hartati, N. S. 2017. Karakterisasi Morfologi Sengon 
(Paraserianthes falcataria L. Nielsen) Hasil Mutasi Radiasi Sinar Gamma. Silvikultur Tropika 8(1): 41-47. 